\title{
O que aconteceu com os que ensinam? O impacto da COVID-19 sobre a rotina e a saúde dos professores universitários
}

\author{
Anelise Rebelato Mozzato \\ Graduada em Psicologia pela Universidade de Passo Fundo - UPF. Especialista em Gestão Empresarial pela \\ Universidade Federal de Santa Catarina - UFSC. Mestrado em Educação pela UPF. Doutora em Administração \\ pela Unisinos. Docente titular do PPGAdm/UPF. \\ $\square$ anerebe@upf.br \\ Maira Sgarbossa \\ Graduada em Ciências Contábeis pela Universidade de Passo Fundo - UPF. Especialista em Controladoria e \\ Gestão Tributária pela Universidade de Passo Fundo -UPF. Mestranda em Administração do Programa de Pós- \\ Graduação em Administração da UPF/PPGAdm. Bolsista CAPES. \\ ه114278@upf.br
}

\section{Fernanda Rebelato Mozzato}

Graduada em Psicologia pela Universidade de Passo Fundo - UPF. Acadêmica de Medicina na UNIVALI.

$\triangle \underline{\text { mozzato97@gmail.com }}$

\section{Resumo:}

A pandemia da COVID-19 atingiu de modo distinto docentes e discentes, bem como o sistema educacional, agravando as muitas assimetrias latentes já existentes. Com a necessidade do distanciamento social, o ensino universitário foi levado a rever suas práticas educacionais, que já clamavam por mudanças há muito tempo. Em curto espaço temporal, professores e alunos universitários precisaram se adaptar ao modelo remoto de ensino. Desse modo, este ensaio teórico tem como objetivo debater e alçar reflexões sobre o impacto da pandemia da COVID-19 na rotina e na saúde do professor universitário. Por meio da revisão de literatura, destacou-se algumas das diversas consequências que a pandemia trouxe para a sociedade e, sobretudo, para a educação, cujas fragilidades, são expostas frente à pandemia, a qual impõe incertezas e desafios diversos (visíveis e invisíveis), que acometem o trabalho dos docentes em diversos aspectos, abrangendo a vida pessoal, social, econômicofinanceira, saúde física e psíquica diretamente relacionadas a atividade laboral, levando estes a sentir um misto de prazer e sofrimento no trabalho. Além disso, as mazelas vivenciadas pela exigência de um novo modelo educacional, o qual tem como base, maior utilização da tecnologia, somou-se aos demais desafios, sobretudo para os docentes. Diante disso, por meio de algumas indagações e provocações, leva-se o leitor a pensar sobre as situações e consequências (im)postas pela COVID-19, em busca de respostas, caso houverem. Nessa lógica, por mais que paradoxal, visualiza-se a promoção de um processo de ensino-aprendizagem mais criativo e reflexivo, seja na modalidade presencial, ou mesmo no ensino remoto.

Palavras-chave: COVID-19, pandemia, ensino universitário, professor, saúde, rotina.

\section{What happened to those who teach? The impact of COVID-19 on the routine and health of university professors}

\begin{abstract}
:
The COVID-19 pandemic has differently affected teachers and students, as well as the educational system, aggravating the many latent asymmetries that already exist. With the need for social distancing, university education was led to review its educational practices, which had been crying out for change for a long time. In a short time, professors and university students had to adapt to the remote teaching model. Thus, this theoretical essay aims to debate and raise reflections on the impact of COVID-19 pandemic on the routine and
\end{abstract}


health of university professors. Through the literature review, we highlighted some of the various consequences that the pandemic has brought to society and, above all, for education, whose weaknesses are exposed to the pandemic, which imposes uncertainties and diverse challenges (visible and invisible), which affect the work of teachers in various aspects, covering personal, social, economic-financial life, physical and mental health directly related to work activity, leading these to feel a mixture of pleasure and suffering at work. In addition, the problems experienced by the demand for a new educational model, which is based on greater use of technology, added to the other challenges, especially for teachers. Therefore, through some questions and provocations, the reader is asked to think about the situations and consequences (im)posed by COVID-19, in search of answers, if any. In this logic, however paradoxical, we can see the promotion of a more creative and reflective teaching-learning process, whether in the face-to-face modality, or even in remote teaching.

Keywords: COVID-19, pandemic, university education, teacher, health, routine.

\section{¿Qué les pasó a los que enseñan? El impacto de COVID-19 en la rutina y la salud de los profesores universitarios}

\section{Resumen:}

La pandemia de COVID-19 ha afectado de manera diferente docentes y estudiantes, como al sistema educativo, agravando las muchas asimetrías latentes que ya existen. Con necesidad de distanciamiento social, la educación universitaria se vio conduciendo a revisar sus prácticas educativas, que habían estado pidiendo a gritos un cambio durante mucho tiempo. En poco tiempo, profesores y universitarios tuvieron que adaptarse modelo de enseñanza a distancia. Así, este ensayo teórico pretende debatir y plantear reflexiones sobre impacto del COVID-19 la rutina y salud de los profesores universitarios. Através de revisión bibliográfica, destacamos algunas de las diversas consecuencias que la pandemia ha traído la sociedad y, sobre todo, la educación, cuyas debilidades están expuestas la pandemia, que impone incertidumbres y diversos desafíos (visibles e invisibles), que afectan trabajo de los docentes en diversos aspectos, abarcando vida personal, social, económicofinanciera, salud física y mental directamente relacionada con la actividad laboral, llevándolos a sentir una mezcla de placer y sufrimiento el trabajo. Además, los problemas experimentados por la demanda de nuevo modelo educativo, que se basa en mayor uso tecnología, se sumaron los otros desafíos, especialmente para los docentes. Por lo tanto, a través de algunas preguntas y provocaciones, se le pide al lector que piense en las situaciones y consecuencias (im)planteadas por COVID-19, en busca de respuestas, si las hubiera. En esta lógica, por paradójica que sea, podemos ver la promoción de un proceso de enseñanza-aprendizaje más creativo y reflexivo, ya sea en la modalidad presencial, o incluso en la enseñanza a distancia.

Palabras clave: COVID-19, pandemia, educación universitaria, docente, salud, rutina.

\section{INICIANDO O DEBATE}

A pandemia da COVID-19, inegavelmente, trouxe e descortinou uma série de mazelas sociais, além de ter trazido muitas mudanças nas rotinas e nos hábitos da população mundial. Neste contexto não se pode negar as mudanças e repercussões psicossociais geradas pela instauração da crise sanitária (CASTILHO SÁ; MIRANDA; CANAVÊZ, 2020). Assim, também a educação enfrenta muitos desafios e, nesse momento pandêmico, preocupações diversas são inerentes aos sistemas educacionais em todo o mundo. Apesar de "soluções" serem apresentadas por alguns, será que elas foram compatíveis com o atual momento vivenciado? 
Com o choque econômico e social apresentado pela pandemia, Kramer e Kramer (2020) salientam a necessidade de reformulações relacionadas ao mundo do trabalho. Portanto, é necessário que se pense na pandemia e na realidade pós-pandêmica, entendendo esta realidade como um meio em demanda de transformações, readaptações e reinvenções da vida cotidiana, criando e recriando o novo normal constantemente (MCKIMM et al., 2020). Apesar da crise ser mundial na educação e em diversos segmentos, havendo muitas incertezas, temores e desafios, este ensaio teórico se detém na realidade da educação brasileira, com foco no impacto da covid-19 sobre a rotina e saúde dos professores universitários, impelindo ao questionamento apresentado no título deste trabalho: o que aconteceu com os que ensinam?.

No cenário da crise educacional no Brasil, muitos desencontros entre decisões governamentais relacionadas à educação dificultaram as tomadas de decisões, sobretudo relacionadas à esfera pública, fato que acarretou atrasos superiores a um semestre letivo em diversas instituições e muitas incertezas para esse ano que inicia. Em contrapartida, mesmo não isenta das incertezas, a esfera privada agiu rapidamente introduzindo a reposição das aulas remotamente, utilizando plataformas diversas, cuja utilização, muitas vezes, já era feita por unidades institucionais, facilitando o manejo e ampliando as possibilidades e recursos. A evidente desigualdade social e de oportunidades no Brasil foi amplificada, desfavorecendo ainda mais os estudantes com baixa renda no acesso e continuidade da educação.

As medidas de distanciamento social necessárias e compulsórias para impedir a disseminação da COVID-19 levou docentes e discentes da esfera pública e privada, habituados a frequentar o espaço físico de ensino, a reinventar o processo ensino-aprendizagem no ambiente do lar e em um curto período de tempo. Desse modo, podemos dizer que o distanciamento social acarretou na aproximação virtual? Ou estamos cada vez mais distantes uns dos outros? De imediato e com a mente conturbada devido a tantas incertezas impostas, as assimetrias educacionais já existentes foram agravadas, e as dificuldades advindas com o conhecimento imaturo frente a utilização das tecnologias digitais intensificam as lacunas no processo educacional (TELES et al., 2018).

No livro "A cruel pedagogia do vírus", Santos (2020) expõe muito didaticamente as fragilidades inerentes à atual sociedade neocapitalista. As fragilidades da sociedade contemporânea são evidenciadas frente às demandas e mudanças trazidas pela pandemia, o que traz diversas incertezas e desafia os moldes capitalistas correntes e a acessibilidade e 
eficácia dos serviços e bens públicos, dos direitos sociais e trabalhistas e faz-se questionar, ainda, o papel do Estado na garantia da vida da população (LEITE, 2020). Dado o exposto e o foco deste ensaio teórico, urgem questionamentos tais como: Até que ponto as pessoas estão vivenciando a epidemia da mesma forma? Até que ponto a popular colocação de que "estamos todos no mesmo barco" é verdadeira? Nessa lógica, fica visível que os barcos e as marés não são as mesmas, não é? E em meio a essa tempestade, os menos consultados, ouvidos ou considerados foram os professores, professoras e estudantes (MONTEIRO, 2020).

Segundo Leite (2020), o impacto da pandemia da COVID-19 diferencia-se muito de trabalhador para trabalhador, evidenciando a desigualdade social e de oportunidades existente no Brasil. Também ficam evidentes as diferenças entre o ensino público e o privado, e até mesmo diferenças no próprio ensino público. Dada tal realidade, fica a dúvida quanto ao real aumento desse gap e como ele vai impactar diretamente nas gerações futuras, na sociedade brasileira. Lhuilier (2020) acrescenta que a situação emergente é paradoxal, principalmente devido à possibilidade de maior precarização do trabalho e, por outro lado, à abertura de oportunidades para novos aprendizados. Ademais, Giust-Desprairies (2020) contribui, ao articular com o contexto do trabalho, apontando acerca das consequências sociológicas e psicológicas decorrentes da pandemia, os quais os docentes universitários encontram-se.

Muitas são as pesquisas relacionados ao impacto da Covid-19 em diferentes espaços socias, principalmente os que retratam a realidade dos profissionais da saúde devido à exposição desses na linha de frente no combate às consequências patológicas do vírus (DINAKARAN et al., 2020; SANTOS et al, 2020; SHIGEMURA et al., 2020; ZHANG et al., 2020). No entanto, também há trabalhos, por mais que em menor número, relacionados a realidade e a saúde dos professores universitários (ARAÚJO et al., 2020; SHIGEMURA et al., 2020; SILVA et al., 2020; SUNJAYA; HERAWATI; SIREGAR, 2021). Dada a atualidade e a emergência do tema, fica evidente a necessidade de mais debates sobre as questões que despontam desta crise pandêmica, inclusive sobre as atuais adversidades no ensino universitário, na qual os docentes encontram-se imersos em constantes desafios (KLAPKIV; DLUHOPOLSKA, 2020; MACHYNSKA; DZIKOVSKA, 2020; NUERE; MIGUEL, 2020; WATERMEYER et al., 2020).

Diante do exposto, este ensaio teórico tem como objetivo debater e alçar reflexões sobre o impacto da COVID-19 na rotina e na saúde do professor universitário. Justifica-se a 
realização deste trabalho em razão da emergência do tema, acreditando que ele trará contribuições tanto práticas, como teóricas e sociais. Visando a reflexão aqui proposta, após essas considerações iniciais este ensaio teórico apresenta um panorama da Covid-19 e seus impactos, sobretudo no contexto da educação, abordando mais especificamente sobre o trabalho do professor universitário, seguido pelos impactos dela na saúde física e emocional dos docentes. Por fim, considerações finais são apresentadas.

\section{COVID-19 E SEU IMPACTO NO TRABALHO DOCENTE}

“[...] Sou professora na pandemia. Desabafar a minha dor, pois desde março eu moro no computador. É google meet, aula síncrona e assíncrona. É uma novela pra compartilhar a tela. É o aluno que não liga o microfone. Abre essa câmara e me diga o seu nome." (NICOLAU, 2020).

A doença pandêmica do século, a COVID-19, trata-se de uma doença causada pelo novo coronavírus (SARS-CoV-2), conhecido popularmente como coronavírus (OPAS, 2020). Da família dos vírus, a COVID-19 acomete o sistema imunológico, podendo chegar á insuficiência respiratória (WHO, 2020; TESINI, 2020). Devido a sua fácil propagação, protocolos de higiene e isolamento social foram desenvolvidos com o intuito de evitar e lentificar a proliferação do SARS-CoV-2 (BRASIL, 2020; WHO, 2020). Além das ações governamentais direcionadas à saúde, mudanças bruscas nos demais segmentos estão em curso.

O trabalho remoto se tornou uma realidade, que utilizando-se da tecnologia da informação possibilita a execução do trabalho em local diferente do convencional (MESSENGER, 2019). Tal realidade impactou também a educação em todo o mundo. No Brasil as aulas presenciais sessaram prontamente e o Ministério da Educação (MEC) autorizou, em caráter excepcional, as aulas a distância (normativas da Portaria nº 345/2020), inclusive, em 17 de abril foi publicada uma portaria autorizando tal modalidade até o final do ano de 2020. No início de 2021 ainda sob efeitos da Portaria 1.038, de 7 dezembro 2020, o MEC delibera que as atividades letivas deverão ocorrer de forma presencial a partir de $1^{\circ}$ de março de 2021 (podendo ainda ser suspensas por determinação das autoridades locais) observando os protocolos de biossegurança para o enfrentamento da pandemia, podendo ainda fazer uso de recursos educacionais digitais para a integralização da carga horária das atividades pedagógicas. 
Realidade posta, inegavelmente as universidades comunitárias e particulares tiveram maior facilidade em ingressar no modelo do ensino remoto, tanto por conta das condições socioeconômicas das próprias Instituições, quanto pelas condições diferenciadas da maioria dos alunos. Assim, as aulas puderam ser seguidas de forma remota em 2020, de modo a não perder os semestres e o ano letivo. Por outro lado, as universidades e institutos federais enfrentaram uma realidade distinta, sendo que a maioria delas ficou sem aulas no primeiro semestre do ano, e enfrentaram diversos empasses para o reestabelecimento via remota no segundo semestre letivo. Entretanto, mesmo com a retomada remota da educação, tardia ou não, até que ponto o processo ensino-aprendizagem foi efetivo? O conteúdo programado foi repassado, mas o aluno aprendeu? Ou o professor fez de conta que ensinou e aluno fez de conta que aprendeu?

Concomitante a crise econômica que intensifica as desigualdades sociais no Brasil, a crise sanitária se alia e assola a sociedade brasileira. Como referem Castro et al., (2020), estratégias e planejamentos emergenciais precisaram ser implementados em segmentos diversos para minimizar os impactos negativos da pandemia. A desigualdade percebida no acesso digital, como afirmam Beaunoyer, Dupéré e Guitton (2020), se acentuaram com a COVID-19. Na visão dos autores, tal fato é preocupante porque ter acesso digital não é mais apenas uma comodidade, mas uma necessidade. Essa disparidade digital é notória na educação, inclusive superior, seja na esfera federal, estadual ou particulares. Contudo, com a pandemia muitas mudanças foram necessárias, exigindo adaptações imediatas por parte das pessoas, realidade posta também para alunos e professores de todas as esferas (pública e privada) e níveis (básico, médio e superior). Quanto ao trabalho do docente universitário, este vem sendo readaptado e questionado por ele próprio, além da sociedade.

No século XXI o uso da tecnologia na educação é uma realidade crescente (ONYEMA; DEBORAH, 2019). Entretanto, antes da pandemia, tal utilização ainda estava em debate e sendo inserida paulatinamente no processo de ensino-aprendizagem. Com a COVID-19 a tecnologia proporcionou a continuidade do acesso à informação, o intercâmbio de conteúdos e a disponibilização de materiais em formatos diversos, como também a ocorrência de situações de interação, colaboração e comunicação entre aluno e docente, pesquisador e pesquisado (MAIA; SILVA, 2020), caracterizando-se como uma estratégia de continuidade das pesquisas. Por vezes abusivas e excessivas? Por mais que se tivesse consciência em relação à quarta revolução industrial (revolução 4.0), antes da pandemia muitos docentes não estavam 
dispostos a sair da sua zona de conforto, quebrando paradigmas relacionados a tecnologia e seus usos.

Para além do ensino à distância, a modalidade do teletrabalho se tornou a realidade dos docentes universitários. Por mais que não se possa negar uso dessa modalidade de trabalho e seus benefícios, como otimização de tempo e redução de custos, diversas dificuldades são inerentes à prática, como a necessidade de capacitação, dificuldade de comunicação, fragilidades na avaliação, problemas com equipamentos tecnológicos, entre outros (FILARDI; CASTRO; ZANINI, 2020). Diante de tal realidade fez-se necessário a rápida releitura das práticas educacionais, embora pesquisas já revelavam que o processo de ensinoaprendizagem clamava por mudanças, incluindo a utilização de tecnologias digitais e metodologias ativas, sendo o aluno o protagonista do processo ensino-aprendizagem (PAIVA et al., 2016; WELTER et al., 2020; SOBRAL, 2020), ainda haviam resistências. Nesse contexto, docentes e alunos trocam o quadro e as carteiras escolares, pelo uso intensificado de telas e aplicativos digitais. Será esse o futuro da educação? Vai imperar a aula remota? Presencial? Híbrida?

Tanto a vida pessoal, quanto o trabalho do professor universitário foi impactado abruptamente. Assim, cada docente teve que voltar o olhar para a sua própria prática profissional, muitas vezes até "esquecendo" da sua vida pessoal. Desde março de 2019, o docente "mora em um computador". Diante do ocorrido surgem muitas indagações: Quais foram os sentimentos que permearam e ainda permeiam o docente? As capacitações oferecidas pelas instituições em “tempos normais", puderam ser revisitadas? Foram úteis? Por mais que as atuais adversidades no ensino universitário sejam muitas, como referem Machynska e Dzikovska (2020) e Nuere e Miguel (2020), não se pode negar que os desafios enfrentados pelos docentes apresentam tanto aspectos positivos quanto negativos (MACHYNSKA; DZIKOVSKA, 2020), sobretudo os relacionados à utilização de tecnologias e conexões digitais (NUERE; MIGUEL, 2020; WATERMEYER et al., 2020).

Sabe-se que o ensino a distância de qualidade é possível com instituições presenciais de qualidade, que realizam pesquisa, ensino e extensão. Então, porque tamanha cobrança sobre o docente, exigindo-o aulas "fecundas", quando nem mesmo a instituição cumpre seu papel na "qualidade" exigida? Ou trata-se de uma cegueira docente frente às estratégias didáticas? Onde cabe o papel do aluno nesse processo? E da comunidade acadêmica? Talvez, 
um dos legados da COVID-19 está em pensar um novo modo de promover ações educacionais que integrem ensino-pesquisa e extensão, presencial e remoto, estratégias tradicionais e modernas, metodologias ativas e tradicionais.

A Educação à Distância (EAD) já era uma estratégia utilizada parcialmente, sobretudo em instituições particulares (VARANDA; ZERBINI; ABBAD, 2010). Ela consiste em uma abordagem de ensino-aprendizagem pautada na separação física, que possibilita diferentes formas de interação dos discentes entre si e com seus docentes (VARGAS; ABBAD, 2006). Por mais que a EAD já ocupava um espaço na sociedade, não se nega a mudança disruptiva na educação. Sem serem avisados ou consultados ou até mesmo capacitados, rapidamente os docentes foram "obrigados" a trabalhar com ferramentas tecnológicas diversas, necessárias ao ensino remoto. Assim, sentiram a pressão de novas demandas, inclusive o medo de perder o emprego ou de não ser capaz de trabalhar nessa "nova" modalidade.

Diante de tal realidade posta, inegavelmente muitas fragilidades do sistema educacional ficaram expostas. Nesse aspecto, Sathler (2020) apregoa que a aprendizagem que já estava em crise no momento pré-pandemia, em virtude da ineficácia do processo de ensino desde a educação básica até a educação superior, sofrerá ainda mais com o modelo tecnológico emergencial na era da COVID-19. Entretanto, com a pandemia e a urgência para a resolução de necessidades do cotidiano e profissionais, mais do que nunca as habilidades digitais foram aceitas como necessária e a conectividade passou a ser a palavra de ordem. Acessar a internet tornou-se a forma para a conexão com a educação, para encontrar o professor e construir o conhecimento. E aqueles (as) que não dispõe dos meios para se "conectar"? Nesse momento, tanto docentes quanto alunos foram desafiados com a transição para a educação on-line (ONYEMA et al., 2020). Assim acontece a disrupção na área educacional, a qual não é só mais apregoada, é uma realidade (im)posta, com muitas dúvidas, tentativas, erros e acertos.

Nesse contexto, novos desafios surgiram para os docentes, sobretudo os relacionados ao manuseio das tecnologias da informação e comunicação (plataformas educacionais diversas). Não obstante, como referem Andel et al. (2020) e Klapkiv e Dluhopolska (2020), fazse necessário pensar e agir no sentido de buscar melhorias dos resultados do aprendizado online, visto a atual e crescente popularidade dessa modalidade de ensinoaprendizagem. Torna-se fundamental o entendimento sobre como é possível facilitar a 
experiência de aprendizado para os usuários nesses ambientes virtuais, implementando mudanças e modernização na comunicação em geral, tendo como foco as formas de aprendizado virtual e suas especificidades. Realidade posta, surgem questionamentos: Será que o ensino remoto em muitas realidades, não veio para ficar? Ainda se faz necessária a presença física para reuniões de colegiado? Quanto foram produtivas as capacitações remotas dos próprios docentes? E a ideia cultivada por muitos docentes e alunos de que o ensino a distância não era produtivo, ainda é lavrada, foi reforçada ou extinta? Enfim, quantas oportunidades a "presença virtual" ofereceu e poderá fornecer?

Dado o fato de que o ensino universitário tem passando por desafios sem precedentes, os docentes universitários precisaram enfrenta-los, assumindo mudanças diversas na sua rotina de trabalho e, muitas vezes, um tanto solitários (mesmo havendo apoio das universidades), de acordo com a sua disciplina, procurar ferramentas que lhes permitam um contato efetivo com os alunos, visto que eles se tornam os principais atores do processo ensino-aprendizagem (NUERE; MIGUEL, 2020). Não obstante, em meio ao aprendizado de tais plataformas educacionais e técnicas de ensino remoto que facilitem a aprendizagem, os docentes tem o desafio de acolhimento dos discentes e a tarefa de estimulá-los na busca da construção do conhecimento de modo diferente, estimulando-o a ser mais protagonista do seu aprendizado.

Nesse momento ímpar vivenciado, inegavelmente o uso de tecnologias educacionais juntamente com abordagens de ensino-aprendizagem apropriadas tornam-se muito importantes. E o que acontece com os alunos que não dispõe desse acesso? Por mais que pesquisas já revelavam que o processo de ensino-aprendizagem clamava por mudanças, incluindo a utilização de tecnologias e metodologias ativas, ainda haviam resistências. Só dessa maneira diferenciada se consegue vislumbrar a possibilidade de uma educação não bancária, tanto preconizada por Freire como a educação libertadora (2005; 2009). Mckimm et al. (2020) reafirmam a necessidade de se transcender a educação bancária, sendo criados espaços para a liberdade, participação e reflexão crítica e dialógica. Não será o momento de aproveitar as mudanças impostas e romper com a rigidez imposta pelo sistema educacional? Quanto às universidades públicas, não chegou a vez de organizar disciplinas em conjunto com outras instituições de ensino, a fim de quebrar os murros que às distanciam? Não estamos vivendo uma virada na percepção pública sobre a ciência e tecnologia, com a presença de 
universidades (públicas e privadas) apoiando a sociedade no combate à pandemia? 0 professor e o estudante são lembrados nesse processo ou fica apenas a cargo da instituição? Quem é a instituição?

Deste modo, com toda essa situação desafiadora exposta, com o findar do ano de 2020 e o início de 2021, os docentes ainda estão tendo vivências paradoxais, tais como o uso e aplicabilidade das tecnologias, espaço da vida pessoal e profissional, rotinas, saúde física e mental. Tais paradoxos fazem parte da atual rotina dos docentes. Não obstante, como referem Ferreira e Barbosa (2020), antes da pandemia e isolamento social, as jornadas de trabalho dos docentes já eram longas, e o contexto atual fez aumentar o tempo de preparação da aula virtual, que inclui a antecipação do manuseio da tecnologia. Os autores também afirmam que a autonomia do docente sobre o seu próprio trabalho ficou mais prejudicada durante a pandemia, tendo a impossibilidade de domínio sobre a própria imagem, com sensação de menor controle do trabalho e aumento de manipulações e acusações, tudo potencializado pelo ensino remoto.

Ademais, o ensino remoto demanda adaptação, capacidade de criar, editar e publicar conteúdos, inclusive imaginação, esforço e produção, além do habitual (CAMACHO et al., 2020). Desse modo, refere Oliveira (2004) que o profissional pode sofrer com a fragmentação da identidade e desvalorização da profissão, devido à necessidade de realizar diversas tarefas que não consistiam na prática habitual da profissão, dispendendo mais tempo para o trabalho e elevando a carga laboral, visto que passaram a realizar suas atividades exclusivamente, ou quase, em casa. Assim, o trabalho do professor universitário foi impactado abruptamente e, necessariamente, cada docente teve que voltar o olhar para a sua própria prática profissional.

Por mais que as atuais adversidades no ensino universitário sejam muitas, como referem Machynska e Dzikovska (2020) e Nuere e Miguel (2020), não se pode negar que os desafios enfrentados pelos docentes apresentam tanto aspectos positivos quanto negativos (MACHYNSKA; DZIKOVSKA, 2020), sobretudo os relacionados à utilização de tecnologias e conexões digitais (NUERE; MIGUEL, 2020; WATERMEYER et al., 2020). Mesmo com os inegáveis desafios, experiências positivas têm sido vivenciadas por Universidades, como exemplificam Klapkiv e Dluhopolska (2020). Os autores salientam que, paradoxalmente, docentes universitários enfrentam o desafio de identificar e aprender a trabalhar com as ferramentas e tecnologias apropriadas para o ensino remoto e, por outro lado, têm a oportunidade do 
aprendizado e desenvolvimento das suas habilidades (talvez inimagináveis) em tais plataformas educacionais. Não se pode negar que a emergente migração on-line por parte das universidades gerou, em muitos docentes, uma disfuncionalidade significativa, perturbando seus papéis pedagógicos e de suas vidas pessoais (WATERMEYER et al., 2020).

No que tange ao espaço da vida pessoal e profissional do docente, não se pode negar as conturbações nesse momento em que o fazer pedagógico acontece em casa, no espaço da vida pessoal. Losekann e Mourão (2020) falam do Home Office como resposta à imposição do momento, afirmando que são muitos os desafios dos trabalhadores na busca do equilíbrio entre as tarefas profissionais e domésticas. Torna-se notória a intensificação do trabalho docente e a vulnerabilidade que o acomete, justamente no sentido referido por Lhuilier (2020) de que, no atual momento de pandemia tem sido evidenciadas diversas dimensões de vulnerabilidade no mundo do trabalho, repercutindo em dilemas relacionados à saúde do trabalhador. No entanto, a realidade do labor em casa, não é uma modalidade recente. Castells (2008) já referia que o rápido avanço da tecnologia possibilitou a muitas pessoas realizar seus trabalhos em qualquer lugar, até mesmo em casa, apontando, ainda, que tal prática poderia se tornar uma tendência.

As condições do distanciamento devido à Covid-19 impuseram aos docentes a busca por outras formas de organização pedagógica para manutenção da rotina acadêmica dos alunos. Diversos desafios relacionados ao ensino remoto, tais como a adaptação e flexibilização em relação à uma nova forma de ensino e a aprendizagem, utilização das ferramentas tecnológicas para o ensino, gerou sentimento de insegurança, incompetência e dúvidas; alteração na motivação e engajamento dos alunos no ambiente virtual; dificuldades enfrentadas pelos estudantes que impactam também na relação pedagógica; as demandas e cobranças institucionais se agravaram (GODOI et al., 2020). Nesse contexto, Losekann e Mourão (2020), ao tratar do Home Office como resposta à imposição do momento, afirmam que muitos são os desafios dos trabalhadores na busca do equilíbrio entre as tarefas profissionais e domésticas.

Logo, pode-se dizer que o contexto educacional tornou-se provocador de tensão e estresse, e como consequência, os docentes sentem-se cada vez menos estimulados pelo trabalho, resultando em um círculo vicioso de sofrimento e adoecimento (MOREIRA; RODRIGUES, 2018). Fica evidente o trabalho como fonte de prazer e sofrimento, no sentido 
posto por Dejours (2004). O prazer definido pelo autor como o que mobiliza o sujeito no sentido de realização pessoal, reconhecimento e gratificação e o sofrimento inerente à existência. A sobrecarga de trabalho, distintamente impacta a vida do docente, sua autonomia, suas interações sociais e a possibilidade de exercer seu trabalho (CANGUILHEM; CAPONI, 1995).

Longe das salas de aula, o aumento do volume e horas de trabalho, bem como o compartilhamento do espaço de trabalho, em muitos casos, com o espaço da família, vem desencadeando nos docentes ansiedade e sobrecarga de trabalho. Um possível problema de trabalhar em casa de acordo com Grant, Wallace e Spurgeon (2013) está que a sobreposição causada pelo trabalho físico pode causar problemas de saúde mental, incluindo trabalho excessivo. Mencionam os autores que continuar pensando no trabalho ainda pode permanecer após o computador ter sido desligado. O lar é visto como um local de restauração e misturar trabalho e atividades domésticas no mesmo local causar impacto sobre o bemestar mental e físico. Como continuar mantendo esse local "sagrado" como restaurador?

Dado o exposto, algumas mudanças na rotina dos docentes ficam explícitas. Assim, com a singularidade da pandemia, estudos já revelam muitas mazelas, inclusive as relacionadas à saúde física e mental das pessoas. Especificamente relacionado ao trabalho docente, estudos como o de Araújo et al. (2020) retratam o explícito adoecimento desta categoria, sobretudo em razão das inúmeras incertezas (medo, insegurança), o que eleva o nível de estresse, ansiedade e depressão, induzindo muitas vezes a exaustão. Souza et al. (2020) lembram, que a interrupção das atividades acadêmicas presenciais afetou não penas os docentes, mas também os alunos, que passaram a ter sua saúde mental e rendimento acadêmico prejudicados, devido a pandemia.

\section{COVID-19 E A SAÚDE FÍSICA E EMOCIONAL DOS DOCENTES}

“[...] É vídeo aula pra inserir na plataforma. Sedentarismo me deixou fora de forma. É profusão de link pra reunião. É o maremoto chamado ensino remoto." (NICOLAU, 2020).

Antes do contexto pandêmico muitos docentes não viviam essa realidade do trabalho remoto. Para a realização do trabalho docente remoto, algumas condições são necessárias, 
incluindo as ergonômicas. A ergonomia consiste na ciência responsável pelo planejamento dos ambientes, tornando-os apropriados à necessidade de cada pessoa e compatíveis com a tarefa a ser executada (ABERGO, 2016). Diante da necessidade de um novo ambiente laboral, até que ponto todos os docentes os têm? Quantos possuem uma cadeira adequada, um espaço com as condições ergonômicas necessárias?

Com destaque à postura, ter os devidos equipamentos e meios para mantê-la correta e adequada é imprescindível à saúde e bem estar do trabalhador, uma vez que é importante que o peso e esforço sejam devidamente distribuídos entre os ossos, músculos, ligamentos e discos (MOFFAT; VICKERY, 2002). Até que ponto que os docentes que estão trabalhando remotamente estão conseguindo manter a devida postura? Somada as questões ergonômicas, também se faz necessário o cuidado relacionado a temperatura, som e luminosidade, os quais precisam ser limitados e controlados para que não sejam nocivos ao humano (PANERO; ZELNIK, 2015). Ademais, tratando-se da saúde mental do professor universitário, evidenciase a sua rotina, que era marcada por interações sociais e profissionais. Essas interações são destacadas por Sanicola (2008) e Ruiz e Gerhardt (2012) como fonte de apoio, mesmo que indireto, no enfrentamento de problemas, doenças ou situações difíceis. Logo, surge o seguinte questionamento: qual a importância da coletividade para o enfrentamento da pandemia?

Especialmente para os profissionais ambientados em um contexto universitário em todas as suas características, o isolamento tem o potencial de desencadear diversos sintomas, como agravamento da monotonia e da repetitividade do exercício laboral, podendo consistir em fadiga, estresse, diminuição da concentração, sensação de impotência, solidão, irritabilidade, medos, ansiedade, tristeza, alterações de apetite e sono (PIMENTEL, 1999; PEREIRA NETO; LONDERO-SANTOS; NATIVIDADE, 2019; CEPEDES, 2020; IASC, 2020) que podem evoluir para transtornos psicológicos (ASMUNDSON; ABRAMOWITZ; RICHTER, 2010), sobretudo naqueles que já possuíam alguma desordem psíquica (HUREMOVIC, 2019). O estresse tem acometido a profissão docente, agravando a saúde destes (PEREIRA NETO; LONDERO-SANTOS; NATIVIDADE, 2019) cujo potencial de evolução, pode caracterizar-se em doenças psíquicas, a exemplo de transtornos de ansiedade, depressivos e do pânico (ASMUNDSON; ABRAMOWITZ; RICHTER, 2010). Estamos na era de educadores adoecidos? O que está acontecendo com os que ensinam? 
Tratando-se do sono, a desregulação do seu padrão, por si só, já pode trazer inúmeras consequências à saúde física e mental, sendo causa do aumento do nível de estresse que potencialmente ocasiona tal desregulação e, por tal motivo, criando um ciclo insone. Os fatores estressantes colocam os docentes em um grupo extremamente vulnerável a distúrbios do sono em meio à pandemia. Zhang et al. (2020) apontam a atividade profissional em isolamento e o medo da infecção pelo coronavírus como fatores de risco para a insônia. Além disso, o medo é um dos sentimentos mais presentes frente às incertezas trazidas pelo COVID19. Por ser um sentimento intrínseco à biologia humana, necessário à sobrevivência, com a função de proteger o indivíduo de riscos e ameaças, quando, em excesso, torna-se nocivo (SHIN; LIBERZON, 2010; GARCIA, 2017), provocando desregulação hormonal no corpo humano, aumentando a resposta de hipervigilância que caracteriza a ansiedade, o que pode aumentar os níveis de glicocorticoides na circulação, associados a depressão e ansiedade (SHIN; LIBERZON, 2010).

Brooks et al. (2020) e Shigemura et al. (2020) referem que a saúde mental de pessoas em isolamento social em razão da pandemia, pode ser muito prejudicada devido ao medo de infectar-se ou infectar membros da família. O medo da infecção é potencializado em razão do exponencial aumento do número de mortos pela COVID-19. Como lidar com as frustrações geradas pelo impacto do coronavírus? Asmundson e Taylor (2020), diante dessa realidade, delinearam o constructo "coronafobia" para caracterizar o sofrimento e medos originados pela COVID-19. Ademais, Lee (2020) elaborou a Escala de Ansiedade de Coronavírus, um instrumento para a avaliação da saúde mental dos indivíduos frente à pandemia e o estudo de Lee, Jobe e Mathis (2020) aborda as características e consequências da ansiedade disfuncional pelo coronavírus. Cabe assinalar que ao tratar-se de seres humanos, a diversidade de reações frente a uma mesma situação é intrínseca (WISNER, 1994). Logo, a maneira como as consequências do trabalho remoto afeta as pessoas é variado, mesmo tratando-se de um grupo homogêneo como o dos docentes universitários, abordado neste trabalho. É conveniente, diante disso, a análise da determinação social do processo saúdedoença.

A doença, tal como o sofrimento, não deve ser definida somente por medições fisiopatológicas, uma vez que os sintomas são sentidos e interpretados com diferentes significados e graus pelos sujeitos, prejudicando de forma distinta o impacto sobre sua vida, sua autonomia, suas interações sociais e a possibilidade de exercer devidamente seu trabalho 
(CANGUILHEM; CAPONI, 1995). Além disso, alguns estressores já são intrínsecos à rotina do professor universitário, esses englobam a necessidade de atualização constante, excesso de demandas de trabalho, prazos, dificuldade de relacionamento com alunos e colegas de profissão, falta de reconhecimento, condições de trabalho inadequadas, entre outros (TARIS; LEISINK; SCHAUFELI, 2017). Vivências de sofrimento e prazer no trabalho fazem parte do trabalho docente (PENA; REMOALDO, 2019), dado o fato de que as atividades laborais muitas vezes exigem além das entregas reais e possíveis, podendo assim, vir a se tornar uma ameaça a eles e, como resultado, gerar vivências de sofrimento (DEJOURS, 1993). A psicodinâmica do trabalho, busca compreender os recursos necessários ao trabalhador para conservar o equilíbrio mental frente às condições laborais, bem como o uso de estratégias de defesas na busca da transformação e ressignificação das vivências de sofrimento (DEJOURS, 1994), precisa ser resgatada e revisitada no atual momento pandêmico.

Estudos apontam que a pandemia impacta os(as) docentes(as) universitários(as), debilitando sua saúde física e mental, podendo estar relacionado a fatores já referenciados por Pimentel (1999), Pereira Neto, Londero-Santos e Natividade (2019), Cepedes (2020) e Iasc (2020), tais como: aumento das dores de cabeça, dificuldade de concentração, maior incidência de tristeza, irritação, esgotamento mental, alterações na rotina do sono, necessidade de remédios de uso contínuo, distúrbios alimentares, dentre outros males. Além disso, muitas vezes, por não conseguir atingir os objetivos propostos pela instituição, e em razão às diversas pressões pertinentes ao manuseio das tecnologias e gravações de aulas, os docentes acabam adoecendo (SILVA et al., 2020). Em equivalência, observações internacionais já revelam o adoecimento docente revelado pelas incertezas, estresses, ansiedade e depressão, induzindo à síndrome do esgotamento profissional (ARAÚJO et al., 2020). Nota-se que muitas são as consequências da pandemia sobre a saúde dos docentes, existindo uma diversidade de reações frente a uma mesma situação. Como controlar tais distúrbios com o aumento da ansiedade? Como os docentes podem lidar com tantas demandas e não se culpar, se porventura não der conta de imediato de todas as questões impostas? Seria um maremoto de aulas e reuniões remotas?

Diante de tantas indagações que se somam ao medo e a angústia de contrair o vírus, perder o emprego, sobrecarga de trabalho e infinitos outros fenômenos que assolam o contexto, está o docente, dando seu melhor e se reinventando junto aos alunos e ao próprio 
sistema educacional. Como forma de síntese, apresenta-se na Figura 1 os principais aspectos abordados nesse ensaio teórico, a fim de destacar e tentar responder à questão que o impulsionou: "o que aconteceu com os que ensinam?"

Figura 1. Figura citada no texto

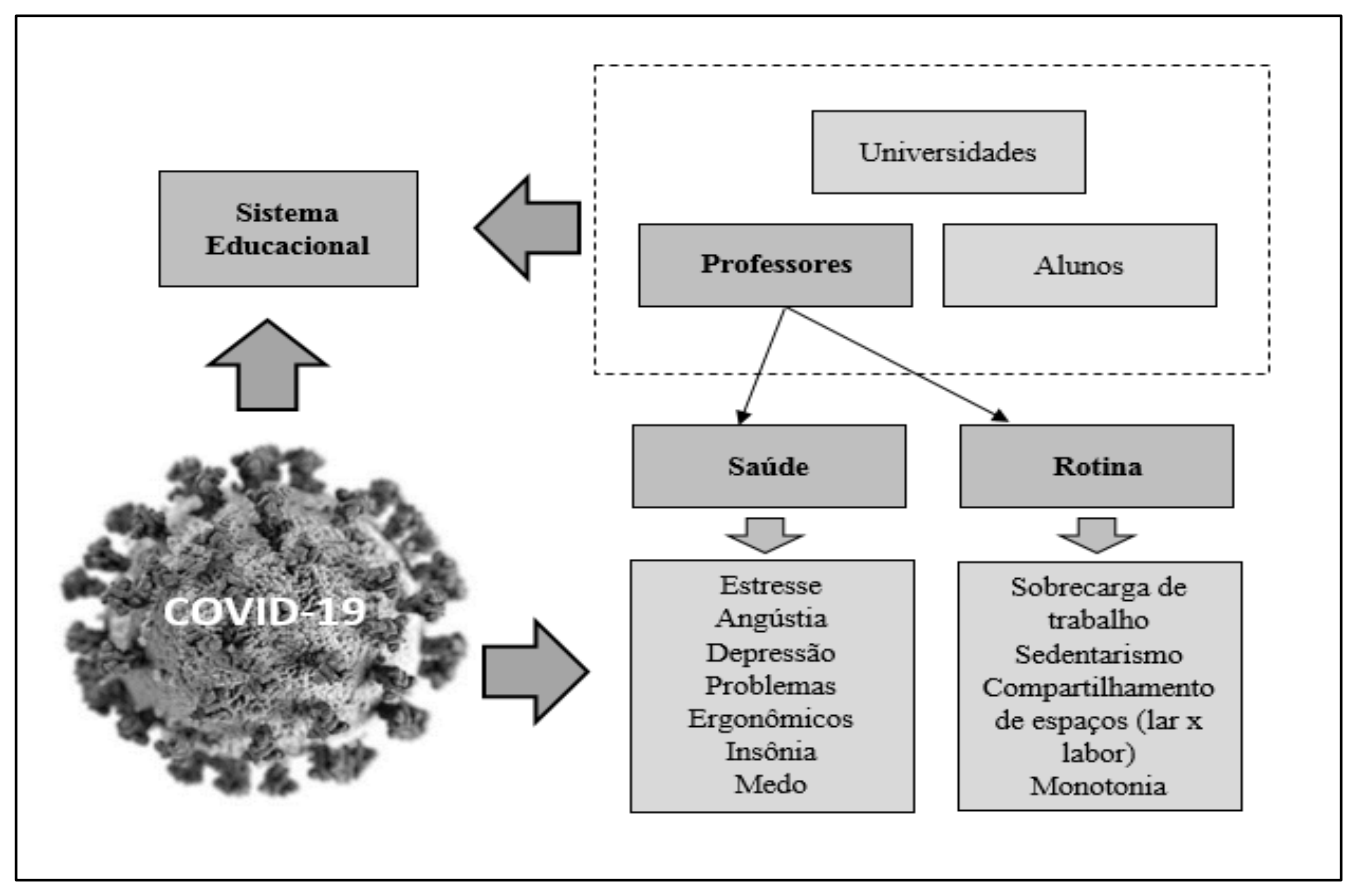

Legenda: Impacto da COVID-19 sobre a saúde e rotina dos docentes universitários Fonte: elaborado pelas autoras (2021).

Observa-se através do exposto na Figura 1, que a pandemia afetou abruptamente o sistema educacional, sobretudo o professor, nesse contexto o universitário, que teve alterações profundas em seu modo de labor (migração do ensino presencial para o remoto) respingando diretamente nos aspectos relacionados à rotina e à saúde. Desse modo, chega-se à conclusão de que a questão do título deste ensaio teórico ainda está com sua resposta em construção, visto que o cenário pandêmico ainda está presente e com consequências ativas. Ou seja, as mudanças estão em curso, experiências estão sendo vivenciadas e em processo de análise. Portanto, será que os docentes ainda são os mesmos? Será que eles serão os mesmos quando a pandemia? o que se conhece até o momento, são algumas das implicações da pandemia sobre o docente, que permanece em fase de adaptação ao cenário (im)posto, que quiçá, poderá nos apresentar, apesar de já notórios resquícios de mudanças, outras, tão clamadas a tempos pela educação. 


\section{CONSIDERAÇÕES FINAIS DO DEBATE}

Chegando ao final deste ensaio teórico, nota-se que não são apresentadas respostas objetivas ao questionamento do título deste, e sim, realizadas reflexões e questionamentos sobre alguns aspectos relacionados ao o que aconteceu e está acontecendo com o professor universitário, até porque, apesar da mudança ter sido disruptiva, ela ainda se encontra em curso. Entretanto, fica visível o real impacto da COVID-19 tanto sobre a rotina do professor universitário, quanto na sua saúde, como também, as desigualdades sociais e as novas relações de ensino e os grandes desafios (visíveis e invisíveis) nos quais a educação está imersa. Além disso, potenciais conhecimentos e aprendizados por parte do docente universitário, inclusive com a possibilidade da promoção de um processo de ensinoaprendizagem mais criativo, reflexivo, dialógico e emancipatório, independentemente de ser presencial ou não, se advogam.

Entretanto, mazelas vivenciadas por conta da COVID-19 estão sendo vivenciadas e um novo modelo educacional passou a ser exigido, o qual tem como base maior utilização da tecnologia. Porém, a dificuldade de acesso à tecnologia, ainda presente em grande parte da sociedade brasileira, se constitui num dos pontos que contribui fortemente para o afastamento dos alunos do processo formativo e nas decisões e ações emergenciais adotadas pelas universidades públicas e privadas. Portanto, fica evidente que a Covid-19 impactou o trabalho dos docentes em diversos aspectos, abrangendo a vida pessoal, social, econômicofinanceira, saúde física e psíquica diretamente relacionadas a atividade laboral, levando estes a sentir um misto de prazer e sofrimento no trabalho. Logo, faz-se necessário revisitar a psicodinâmica do trabalho, a fim de investigar os mecanismos de defesa dos docentes diante às situações causadoras de sofrimento decorrentes do labor.

Associado a tais aspectos, o isolamento social intensificou as preocupações frente a fragilização dos vínculos empregatícios, sobretudo dos docentes, que dentre muitos impactos negativos sobre a esfera do trabalho, houve conturbações entre os espaços pessoais e profissionais, sobrecarga de trabalho, privações de atividades físicas, intensificação do medo (de contrair o vírus, perder familiares e emprego, etc.) e com isso, aumento do nível de estresse, dores de cabeça, acréscimo no uso de medicações, monotonia, riscos ergonômicos e outros. Somado a isso, a constante demanda pela "reinvenção docente e do sistema de ensino", coloca os docentes universitários na esteira da criatividade, obrigando-os ao 
processo de reinvenção, no intuito de "produzir" aulas aprazíveis, diferentes, criativas, que cativem a atenção do aluno, que muitas vezes "fecha a câmara e desliga o microfone" como forma de dizer: "estou aqui, mas não me solicite", ou até mesmo, "estou presente, mas não de fato". Como tornar uma aula "agradável" quando a outra parte não colabora? Sabe-se que muitas vezes o aluno está apenas presente na aula, mas não participa dela, cabendo ao docente, instigá-lo, trazê-lo ao debate. Mas como proceder "criativamente" quando este simplesmente se isola atrás de uma tela de computador e o docente passa a falar para uma multiplicidade de fotos e nomes? Não se trata de uma via de mão dupla? Elaborar aulas criativas para quem?

Contudo, nesse complexo meio de tantas incertezas, medos e transformações, o sistema educacional clama por mudanças e o docente que adoece, tenta como um "beija-flor" amenizar os impactos negativos sobre o processo de aprendizagem dos discentes, a fim de não perder o semestre, ou até mesmo ano letivo. Portanto, diante da realidade vivenciada tanto por docentes, quanto por alunos, faz-se necessário a adoção de um olhar holístico, abrangendo e analisando tudo que os cerca. A realização de mais pesquisas, sobretudo empíricas, se mostra de suma preponderância, uma vez que o isolamento, a mudança drástica de rotina e a necessidade de adaptação a uma realidade ensandecedora impactam negativamente na saúde física e mental do indivíduo. Por fim, poder compreender todo cenário da pandemia e como ela impacta na vida dos docentes acaba por tonar possível promover ações de resolução a medida que responde-se o questionamento inicialmente proposto: 0 que está acontecendo com os que ensinam?

\section{REFERÊNCIAS}

ABERGO. ASSOCIAÇÃO BRASILEIRA DE ERGONOMIA. o que é ergonomia? Disponível em: < https://www.abergo.org.br/>. Acesso em 8. Jun. 2020.

ANDEL, S. A.; VREEDE, T.; SPECTOR, P. E.; PADMANABHAN, B.; SINGH, V. K.; VREEDE, G. J. Do social features help in video-centric online learning platforms? A presence perspective. Computers in Human Behavior. Journal Pre-proof, p.1-8, 2020.

ARAÚJO, F. J. O.; LIMA, L. S. B.; CIDADE, P. I. M.; NOBRE, C. B.; ROLIM NETO, M. L. Impact of Sars-Cov-2 and its Reverberation in Global Higher Education and Mental Health. Psychiatry Research, v. 288, p. 1-33, 2020.

ASMUNDSON, G. J. G.; TAYLOR, S. Coronaphobia: Fear and the 2019-nCoV outbreak, 2020. 
ASMUNDSON, G. J. G.; ABRAMOWITZ, J. S.; RICHTER, A. A.; WHEDON, M. (2010). Health Anxiety: Current Perspectives and Future Directions. Curr Psychiatry Rep. v. 12, n. 4, p. 306-312, 2010.

BEAUNOYER, E.; DUPÉRÉ, S.; GUITTON, M. J.COVID-19 e desigualdades digitais: impactos recíprocos e estratégias de mitigação. MedEdPublish, v. 9, n. 1, 2020.

BRASIL. MINISTÉRIO DA SAÚDE. Coronavírus (COVID-19): Sobre a doença. Disponível em: <https://coronavirus.saude.gov.br/index.php/sobre-a-doenca>. Acesso em 15 de julho de 2020.

BROOKS, S. K.; WEBSTER, R. K.; SMITH, L. E; WOODLAND, L.; WESSELY, S.; GREENBERG N, N. The psychological impact of quarantine and how to reduce it: rapid review of the evidence. The Lancet, v. 395, p. 912-20, 2020.

CANGUILHEM, G. O.; CAPONI, S. O normal e o patológico. 4. ed. Rio de Janeiro: Forence Universitária. 1995.

CASTELLS, M. A Sociedade em Rede. São Paulo: Paz e Terra, 2008.

CASTILHO SÁ, M.; MIRANDA, L.; MAGALHÃES, F. C. Pandemia Covid-19: Catástrofe Sanitária e Psicossocial. Caderno De Administração, v. 28, p. 27-36, 2020.

CASTRO, B. L. G.; OLIVEIRA, J. B. B.; MORAIS, L. Q.; GAI, M. J. P. COVID-19 e organizações: estratégias de enfrentamento para redução de impactos. Revista Psicologia: Organizações e Trabalho - rPOT, v. 20, n. 3, p. 1059-1063, 2020.

CEPEDES. CENTRO DE ESTUDOS E PESQUISAS EM EMERGÊNCIAS E DESASTRES EM SAÚDE DA FUNDAÇÃO OSWALDO CRUZ. Saúde mental e Atenção Psicossocial na Pandemia COVID-19: Recomendações gerais. Disponível em: < https://renastonline.ensp.fiocruz.br/recursos/saude-mental-atencao-psicossocial-pandemiacovid-19-recomendacoes-gerais >. Acesso em 18 de agosto de 2020.

DEJOURS, C. Uma nova visão do sofrimento humano nas organizações. O indivíduo na organização: dimensões esquecidas. São Paulo: Atlas, 1993.

DEJOURS, C. Psicodinâmica do trabalho: contribuições da escola dejouriana à análise da relação prazer, sofrimento trabalho. São Paulo: Atlas, 1994.

DEJOURS, C. A Metodologia em Psicopatologia do Trabalho. In: LANCMAN, S. e SZNELWAR, L.I. Christophe Dejours - Da Psicopatologia à Psicodinâmica do Trabalho. Rio de Janeiro: Fiocruz, Brasília: Paralelo, 2004.

DINAKARAN, D.; MANJUNATHA, N.; KUMAR, C. N.; SURESH, B. M. Neuropsychiatric aspects of COVID-19 pandemic: a selective review. Asian Journal of Psychiatry, v. 53, p. 102-188, 2020.

FILARDI, F.; CASTRO, R. M. P.; ZANINI, M. T. F. Vantagens e desvantagens do teletrabalho na administração pública: análise das experiências do Serpro e da Receita Federal. Cad. EBAPE.BR, Rio de Janeiro, v.18, n.1, p.2846,2020 .

FREIRE, P. Pedagogia do oprimido. Rio de Janeiro: Paz e Terra, 2005.

FREIRE, P. Educação como prática da liberdade. Rio de Janeiro: Paz e Terra, 2009.

GARCIA, R. Neurobiology of fear and specific phobias. Learn Mem, v. 24, n. 9, p. 462-471, 2017.

GIUST-DESPRAIRIES, F. Reflexão sobre como o confinamento mobiliza nosso ambiente de trabalho individual e coletivo. Caderno de Administração, v. 28, p. 54-60, 2020.

HUREMOVIC, D. Psychiatry of Pandemics: A Mental Health Response to Infection Outbreak. Cham: Springer International Publishing, 2019.

KRAMER, A.; KRAMER, K. Z. The potential impact of the Covid-19 pandemic on occupational status, work fromVhome, and occupational mobility. Journal of Vocational Behavior, v.119, p. 140-149, 2020. 
KLAPKIV, Y.; DLUHOPOLSKA, T. Changes in the Tertiary Education System in Pandemic Times: Comparison of Ukrainian and Polish Universities. Revista Romaneasca pentru Educatie Multidimensionala, v. 12, n. 1, p. 8691, 2020.

LEE, S. A. Coronavirus Anxiety Scale: A brief mental health screener for COVID-19 related anxiety. Journal Death Studies, v. 44, p. 393-401, 2020.

LEE, S. A.; JOBE, M. C.; MATHIS, A. A. Mental health characteristics associated with dysfunctional coronavirus anxiety. Psychological Medicine, p. 1-2, 2020.

LEITE, K. C. A (in)esperada pandemia e suas implicações para o mundo do trabalho. Psicologia \& Sociedade, Sorocaba, v.32, p.1-18, 2020.

LHUILIER, D. E se essa crise mudasse radicalmente o mundo do trabalho. Caderno De Administração, v. 28, p. 89-94, 2020.

LOSEKANN, R. G. C. B.; MOURÃO, H, C. Desafios do teletrabalho na pandemia covid-19: Quando o home vira office. Caderno de Administração, v. 28, p. 71-75, 2020.

MACHYNSKA, N.; DZIKOVSKA, M. Challenges to Manage the Educational Process in the HEI during the Pandemic. Revista Romaneasca for Educatie Multidimensionala, v. 12, n.1, p. 92-99, 2020.

MAIA, M. D. S. de A; SILVA, D. G. da. Práticas pedagógicas em ambientes virtuais de aprendizagem: usos e abusos. EmRede - Revista de Educação a Distância, v. 7, n. 1, p. 81-95, 2020.

MCKIMM, J.; GIBBS, T.; BISHOP, J.; JONES. P. Health Professions' Educators' Adaptation to Rapidly Changing Circumstances. In: THE OTTAWA 2020 CONFERENCE EXPERIENCE. 2020.

MEC - MINISTÉRIO DA EDUCAÇÃO. Portaria MEC no 345, de 19 de março de 2020 - Altera a Portaria MEC nº 343, de 17 de março de 2020. Disponível em: <https://www.in.gov.br/web/dou/-/portaria-n-395-de-15-de-abrilde-2020-252725131>. Acesso em 12 de fevereiro de 2021.

MEC - MINISTÉRIO DA EDUCAÇÃO. Portaria MEC nº 1.038, de 7 de dezembro de 2020 - Altera a Portaria MEC no 544, de 16 de junho de 2020. Disponível em: <https://www.in.gov.br/en/web/dou/-/portaria-mec-n-1.038de-7-de-dezembro-de-2020-292694534>. Acesso em 12 de fevereiro de 2021.

MESSENGER, J. C. Telework in the 21st century: an evolutionary perspective. Cheltenham, UK: Edward Elgar Publishing. 2019.

MOFFAT, M.; VICKERY, S. Manual de manutenção e reeducação postural. Porto Alegre: Artmed, 2002.

MONTEIRO, S. da. S. (Re)inventar educação escolar no brasil em tempos da covid-19. Rev. Augustus, v. 25, n. 51, p. 237-254, 2020.

MOREIRA, D. Z.; RODRIGUES, M. B. Saúde mental e trabalho docente. Estudos de Psicologia, v. 23, n. 3, 2018.

NICOLAU, S. M. Professora na pandemia. Participação: Felipe Bemol. 2020. (3min 28s). Disponível em: < https://www.youtube.com/watch?v=ZzAYLN_atbE >.Acesso em 22. fev. 2021.

NUERE, S.; MIGUEL, L. The Digital/Technological Connection with COVID-19: An Unprecedented Challenge in University Teaching. Technology, Knowledge and Learning, v.10, n. 1, p. 1-13, 2020.

OLIVEIRA, D. A. A reestruturação do trabalho docente: precarização e flexibilização. Educação \& Sociedade, v. 25, n. 89, p.1127-1144, 2004.

ONYEMA, E. M.; DEBORAH, E. C. Potentials of Mobile Technologies in Enhancing the Effectiveness of Inquirybased learning. International Journal of Education (IJE), v. 2, n. 1, p. 1-25, 2019. 
ONYEMA, E. M.; DEBORAH, E. C.; ALSAYED, A. O.; NOORULHASAN, Q.; SANOBER, S. Online Discussion Forum as a Tool for Interactive Learning and Communication. International Journal of Recent Technology and Engineering, v. 8, n. 4, p. 4852-4859, 2019.

OPAS. ORGANIZAÇÃO PAN-AMERICANA DA SAÚDE. Folha informativa: COVID-19 doença causada pelo novo coronavírus. 2020. Disponível em:<https://www.paho.org/bra/index.php?option=com_contente\& iew=article\&id=6101:covid19\&Itemid=875>. Acesso em 17 junho 2020.

PAIVA, M. R. F.; PARENTE, J. R. F.; BRANDÃO, I. R.; QUEIROZ, A. H. B. (2016). Metodologias Ativas de ensinoaprendizagem: revisão integrativa. SANARE, v.15, n. 2, p. 145-153, 2016.

PANERO, J.; ZELNKIK, M. Dimensionamento humano para espaços interiores: um livro de consulta e referências para projetos. Barcelona: Editorial Gustavo Gili, 2013.

PENA, L.; REMOALDO, P. Psicodinâmica do Trabalho: um estudo sobre o prazer e o sofrimento no trabalho docente na Universidade Óscar Ribas. Saúde e Sociedade, São Paulo, v. 28, n. 4, p. 147-159, 2019.

PEREIRA NETO, J. C.; LONDERO-SANTOS, A.; NATIVIDADE, J. C. Estressores da docência como preditores do bemestar de professores do ensino fundamental. Revista Psicologia Organizações e Trabalho, v. 19, n. 3, p. 679686, 2019.

PIMENTEL, G. G. A. A ginástica laboral e a recreação nas empresas como espaços de intervenção da educação física no mundo do trabalho. Revista da Faculdade de Educação Física de Santo André, v. 3, p. 57-70, 1999.

RUIZ, E. N. F.; GERHARDT, T. E. Políticas públicas no meio rural: visibilidade e participação social como perspectivas de cidadania solidária e saúde. Physis Revista de Saúde Coletiva, v. 22, n. 3, p. 1191-209, 2012.

SANTOS, B. S. A cruel pedagogia do vírus. São Paulo: Boitempo, 2020.

SANICOLA, L. As dinâmicas de rede e o trabalho social. São Paulo: Veras, 2008.

SATHLER, L. Educação pós-pandemia e a urgência da transformação digital. 2020. Disponível em: < https://anup.org.br/noticias/educacao-pos-pandemia-e-aurgencia-datransformacao-digital/ >. Acesso em: 5 fev. 2020.

SHIGEMURA, J.; URSANO, R. J.; MORGANSTEIN, J. C.; KUROSAWA, M.; BENEDEK, D. M. Public responses to the novel 2019 coronavirus (2019-nCoV) in Japan: Mental health consequences and target populations. Psychiatry Clin Neurosci, v. 74, n. 4, p. 281-282, 2020.

SHIN, L. M.; LIBERZON, I. The Neurocircuitry of Fear, Stress, and Anxiety Disorders. Neuropsychopharmacology, v. 35, p. 169-91, 2010.

SILVA, A. F.; ESTRELA, F. M.; LIMA, N. S.; ABREU, C. T. A. Saúde mental de docentes universitários em tempos de pandemia. Physis: Revista de Saúde Coletiva, Rio de Janeiro, v.30, n.2, 2020.

SOBRAL, S. R. O impacto do COVID-19 na educação, Observador. 2020. Disponível em: < https://observador.pt/opiniao/o-impacto-do-covid-19-na-educacao/ >. Acesso em: 18. dez. 2020.

SOUZA, T. A.; GOMES, S. M.; GALVÃO, M. H. R.; BARBOSA, I. R. Avaliação do conhecimento sobre a pandemia Covid-19 entre estudantes de graduação do interior do estado Rio Grande do Norte. Revista Sustinere, v. 8, n. 1, p. 23-43, 2020.

TARIS, T. W.; LEISINK, P. L. M.; SCHAUFELI, W. B. Applying occupational health theories to educator stress: Contribution of the job demands-resources model. In: MCINTRYRE, T. M.; MCINTYRE, S.; FRANCIS, D. (Eds.), Educator Stress, Aligning Perspectives on Health Safety and Well-Being. Springer International Publishing: Basel, Switzerland. 2017. 
TELES, G.; SOARES, D. M. R.; SENA, T. B. Q. L.; LIMA, L.; LOUREIRO, R. C. Docência e Tecnologias Digitais da Informação e Comunicação: Matrizes curriculares das licenciaturas. In: CONGRESSO SOBRE TECNOLOGIA NA EDUCAÇÃ̃O, 3. 2018, Fortaleza. Resumos[...] Fortaleza: Cultura Maker na Escola, 2018. p. 57-67.

TESINI, B. Síndrome respiratória aguda grave (Covid-19, MERS e SARS). Manual MSD. 2020. Disponível em: < https://www.msdmanuals.com/pt/profissional/doenças--infecciosas/v\%C3\%ADrus-

respiratórios/coronav\%C3\%ADrus-e-s\%C3\%ADndromes-respiratórias-agudas-covid-19,-mers-e-sars >. Acesso em: 27 novembro 2020.

VARANDA, R. C.; ZERBINI, T.; ABBAD, A. Construção e Validação da Escala de Reações à Interface Gráfica para Cursos de Educação a Distância. Psicologia: Teoria e Pesquisa, v.26, n.2, p.371-380, 2010.

VARGAS, M. R. M.; ABBAD, G. S. Bases Conceituais em Treinamento, Desenvolvimento e Educação (TD\&E). In: BORGES-ANDRADE, J. E.; ABBAD, G.; MOURÃO, L. (Orgs.), Treinamento, desenvolvimento e educação em organizações e trabalho: fundamentos para a gestão de pessoas. Porto Alegre: Artmed. 2006, p. 137-158.

WATERMEYER, R.; CRICK, T.; KNIGHT, C.; GOODALL, J. COVID-19 and digital disruption in UK universities: afflictions and affordances of emergency online migration. Journal Higher Education, p. 1-19, 2020.

WELTER. R. B.; FOLETTO, D. S.; BORTOLUZZI, V. I. Metodologias ativas: uma possibilidade para o multiletramento dos estudantes. Research, Society and Development, v. 9 n. 1, p. 1-21, 2020.

WISNER, A. A inteligência no trabalho: textos selecionados de Ergonomia. Trad. Ferreira. I; Leal, R. São Paulo: Fundacentro, 1994.

WHO - WORLD HEALTH ORGANIZATION. Coronavirus disease (COVID-19) advice for the public. 2020. Disponível em:< https://www.who.int/emergencies/diseases/novel-coronavirus-2019/advice-for-public >. Acesso em: 20 agosto 2020 .

ZHANG, C.; YANG, L.; LIU, S.; MA, S.; WANG, Y.; CAI, Z.; DU, H.; LI, R.; KANG, L.; SU, M.; ZHANG, J.; LIU, Z.; ZHANG, B. Survey of insomnia and related social psychological factors among medical staff involved in the 2019 novel coronavirus disease outbreak. Front Psychiatry, v.11, n.306, 2020.

(cc)) BY

Este trabalho está licenciado com uma Licença Creative Commons - Atribuição 4.0 Internacional. 